\title{
Geoconservação em brejos de altitude: o Parque Estadual Mata do Pau Ferro
}

No Estado da Paraíba, existem inúmeras localidades com grande potencial de turismo ecológico. Muitos desses locais se constituem em Unidades de Conservação, especialmente no tocante aos Parques Estaduais, que servem de espaço de lazer e para práticas de ecoturismo. Porém, existem vários problemas envolvendo o uso e ocupação dessas áreas, tais como: uso inadequado da terra para fins agrários; extração vegetal; comercialização; tráfico da biodiversidade faunística e florística; e construções em locais indevidos. Nessa perspectiva, esta pesquisa buscou analisar o uso e ocupação do espaço que compreende o Parque Estadual Mata do Pau Ferro, no município de Areia/PB, com vistas a avaliar os possíveis problemas e benefícios socioambientais e o potencial ecoturístico local para harmonizar interesses econômicos e conservação e preservação dos recursos naturais, com subsídio à Geoconservação. Para tanto, foram feitos levantamentos bibliográficos, realizou-se pesquisa in loco com eventuais registros fotográficos, aplicação de questionário e processamento de imagem através do sensoriamento remoto e geoprocessamento. Os resultados obtidos ajudaram a concluir que o referido Parque apresenta inúmeros problemas quanto à preservação e conservação, forte intervenção humana e ausência do órgão gestor responsável pela área. Entretanto, notou-se um grande potencial para atividades econômicas, como o ecoturismo.

Palavras-chave: Unidades de Conservação; Uso e ocupação; Potencial Ecoturístico; Areia/PB.

\section{Geoconservation in brejos of altitude: the State Park Mata do Pau}

\section{Ferro}

\begin{abstract}
In the State of Paraíba, there are numerous places with great potential for ecological tourism. Many of these sites are made up of Conservation Units, especially with regard to State Parks, which serve as a leisure space and for ecotourism practices. However, there are several problems involving the use and occupation of these areas, such as: improper use of land for agricultural purposes; plant extraction; commercialization; trafficking in wildlife and floristic biodiversity; and buildings in undue places. In this perspective, this research sought to analyze the use and occupation of the space that includes the Mata do Pau Ferro State Park, in the city of Areia / PB, in order to evaluate the possible socioenvironmental problems and benefits and the local ecotourism potential to harmonize economic and conservation and preservation of natural resources, with subsidy to Geoconservation. For this purpose, bibliographical surveys were carried out, on-site research with eventual photographic records, questionnaire application and image processing through remote sensing and geoprocessing. The results obtained helped to conclude that the Park presents numerous problems regarding preservation and conservation, strong human intervention and absence of the managing body responsible for the area. However, there was great potential for economic activities, such as ecotourism.
\end{abstract}

Keywords: Conservation units; Use and occupation; Ecotourism Potential; Areia/PB.

Topic: Conservação da Biodiversidade

Reviewed anonymously in the process of blind peer.

Elysson Thiago Gomes Barbosa

Universidade Federal da Paraíba, Brasil

http://lattes.cnpq.br/7998948391547412

elyssonthiag093@hotmail.com

Ailson de Lima Marques

Universidade Federal da Paraíba, Brasil

http://lattes.cnpq.br/7731519684534647

marques.ailsonl@gmail.com

Ulisses Dornelas Belmont Neri

Universidade Federal da Campina Grande, Brasil

http://lattes.cnpq.br/5307625837457220

ulissesdbn@globomail.com

DOI: 10.6008/SPC2318-2881.2017.001.0001
Received: 12/02/2017

Approved: 15/05/2017

\author{
Ewerton da Silva Barbosa \\ Universidade Federal da Paraíba, Brasi \\ http://lattes.cnpq.br/9038746208521577 \\ ewertonbabosa1994@hotmail.com \\ Júlia Diniz de Oliveira \\ Universidade Federal do Rio Grande do Norte, Brasil \\ http://lattes.cnpq.br/6771490646111216 \\ juliadiniz.oliveira@hotmail.com
}

Referencing this:

BARBOSA, E. T. G.; MARQUES, A. L.; NERI, U. D. B.; BARBOSA, E. S.; OLIVEIRA, J. D.. Geoconservação em brejos de altitude: o Parque Estadual Mata do Pau Ferro. Nature and Conservation, v.10, n.1, p.1 16, 2017. DOI: http://doi.org/10.6008/SPC2318-2881.2017.001.0001 


\section{INTRODUÇÃO}

Os problemas ambientais advindos da degradação do meio ambiente, por práticas de exploração não-sustentável dos recursos naturais e pelo uso e ocupação desordenada, por exemplo, contribuem significativamente para o incremento dos impactos ambientais, tais como definidos na Legislação Ambiental Brasileira. Frente a essa realidade, impõe-se a necessidade de maior atenção à conservação e proteção de Unidades de Conservação (UC), que enfrentam desafios quanto à delimitação, gestão, proteção e convívio socioambiental; bem como de áreas verdes em geral, capazes de conferir maior qualidade ambiental, e por conseguinte, melhor qualidade de vida.

Diante das problemáticas ambientais ocasionadas pelas ações antrópicas, as UCs com suas inúmeras unidades no Brasil, sem dúvida constituem-se na forma encontrada para diminuir os problemas e o avanço dos diversos tipos de exploração predatório dos recursos naturais. Logo, tornaram-se espaços responsáveis pelas relações de controle ambiental, unindo os interesses humanos e as necessidades para manter a natureza em equilíbrio dinâmico; constitui-se em espaços que a sociedade usufrui, servindo de "refúgio" da realidade e cotidiano urbano em que vive; utilizando-se do meio para práticas intensas de diferentes atividades, entre elas o lazer e o turismo ecológico.

Dentro desse contexto de relações entre homem-natureza, a Geoconservação acaba por expressar que é preciso condicionar uma relação harmônica entre as atividades econômica, a conservação e uso racional dos patrimônios históricos, geológicos e naturais, o que remete necessariamente às questões ambientais e de uso e ocupação do espaço. Destarte, o Estado da Paraíba possui dezessetes UCs, sendo oito delas categorizadas como Parques Estaduais sob a responsabilidade do Governo Estadual, através da Superintendência de Administração do Meio Ambiente (SUDEMA).

Em todos os Parques há problemáticas relacionadas ao uso e ocupação, delimitação e conhecimento físico das áreas (SILVA, 2007; ANDRADE, 2006). Em síntese, os problemas dos Parques paraibanos, assim como da maioria das UCs no Brasil, estão relacionados à gestão frente ao uso e ocupação do espaço. Dessa forma, as ações conjuntas através da gestão integrada tornam menos complexa a implantação e gestão das unidades.

\section{REVISÃO TEÓRICA}

\section{O Geossistema e o conceito de Paisagem}

A Geografia abrange, em sua epistemologia, um complexo conjunto de estudos e objetos, a partir das suas categorias contemporâneas de análise, das quais, destacam-se nessa discussão: Espaço, Região, Lugar, Território e Paisagem. Estes elementos passaram a influenciar as pesquisas e tornaram-se objetos de estudo de tal ciência.

Segundo Suertegaray (2002), os estudos geográficos buscam analisar e interpretar diferentes conceitos ao longo da história, entre eles o de "natureza", discutido na Geografia de forma conjunta com os 
elementos humanos ou dissociado, sendo a Geografia Física a área responsável por aprofundar os estudos desse conceito.

O estudo da Geografia, dentro das questões ambientais, buscou, na construção de seu conhecimento, analisar a natureza de forma integrada, passando a utilizar nos anos 1920 o método sistêmico para promover essa análise, buscando com isso uma integração. "Ao buscar este caminho, construíram-se conceitos como o de Geossistema, que, por sua vez, ultrapassa na sua construção a integração do conhecimento da natureza. Ultrapassa, porque inclui o homem (a ação do homem) neste contexto" (SUERTEGARAY, 2002).

De acordo com Troppmair et al. (2006), o termo Geossistema teve como precursor na Geografia Sotchava em 1960. Sua contribuição mostra que um Geossistema é uma dimensão do espaço terrestre, ocorrendo circulação de energia e matéria dentro de um sistema natural, complexo e integrado, fazendo com que os diversos componentes naturais se encontrem sistematicamente ordenados, e quando interagindo com a sociedade, formem o espaço geográfico, no qual ocorre a exploração biológica praticada pelo homem.

Entendidos os Geossistemas como um aporte metodológico para a Geografia Física (estudo da organização espacial dos Geossistemas), contribuindo bastante nas análises ambientais, e como unidades naturais integrais, pode-se distinguir suas modificações e transformações como resultantes das ações antrópicas dos diferentes tipos de ocupação, interação e/ou exploração (NASCIMENTO et al., 2004).

Para Amorim et al. (2008), os Geossistemas são definidos como fenômenos naturais (aspectos geomorfológicos, climáticos, hidrológicos e fitogeográficos) que englobam os fenômenos antrópicos (aspectos sociais e econômicos). Somados, estes fenômenos representam a paisagem modificada ou não pela sociedade.

Em síntese, Geossistema compreende aspectos naturais/físicos e humanos (socioeconômicos). Logo, a análise Geossistêmica é um recurso metodológico para analisar a interação entre as atividades humanas e os recursos naturais existentes em um determinado espaço. Amorim et al. (2008) ressaltam que, no estudo dos Geossistemas, o conceito de paisagem é a principal categoria de análise. Bertrand (1971) define a paisagem como certa porção do espaço, resultante da interação dinâmica e instável de atributos físicos, biológicos e antrópicos, que, reagindo dialeticamente uns sobre os outros, fazem dela um conjunto único e indissociável.

Christofoletti (1998) atribui à paisagem a concepção de conceito-chave da Geografia que possibilita a compreensão do espaço como um sistema ambiental, físico e socioeconômico, com estruturação, funcionamento e dinâmica dos elementos físicos, biogeográficos, sociais e econômicos. As relações e distribuições espaciais desses fenômenos são compreendidas na atualidade com o estudo da complexidade inerente as organizações espaciais.

Nesse sentido, as ciências da natureza chegam à concepção que a paisagem é uma herança que vem se adequando, nas últimas décadas, às necessidades humanas e naturais. Assim, fica perceptível que a 
ocupação e uso territorial não se baseiam apenas em espaços delimitados, mas em reflexos da dinâmica de exploração.

Dentro do contexto de Geossistemas, em suas definições encontra-se a categoria de análise das Unidades de Paisagem; delimitá-las é algo complexo que envolve atributos do sistema natural e antrópico, permitindo identificar os referentes atributos responsáveis pela dinâmica da paisagem, "como também identificar principais fragilidades ambientais de cada unidade, elemento essencial na gestão do território" (AMORIM et al., 2008). As Unidades de Paisagens, dessa maneira, se individualizam através dos aspectos e componentes físicos/naturais.

Diante disso, alguns determinantes e discriminações, como grau de recorrência ambiental e vulnerabilidade às interferências antrópicas, que acabam por afetar em algumas características do sistema causando pequenas alterações, por exemplo, tornam-se essenciais ao planejamento e gestão territorial por compreender as condições da biodiversidade, sua organização e exploração (TROPPMAIR et al., 2006).

Por fim, a análise geossistêmica é um método proposto pela Geografia que pode analisar a dialética existente entre os elementos físicos, biológicos e sociais num determinado espaço ou paisagem, ou seja, a relação homem-natureza. Logo, tal método pode ser útil para avaliar a interação entre as ações humanas e os aspectos naturais da paisagem, o que ocorre em diversas atividades, a exemplo da Gestão Territorial e do Ecoturismo.

\section{Gestão Territorial e Ecoturismo}

A gestão territorial constitui-se em uma ferramenta que pode garantir igualdade na questão territorial, contribuindo para melhorar a qualidade de vida da sociedade. Sendo assim, tem-se a gestão territorial como mecanismo disciplinador das ações antrópicas no meio ambiente, e que tem sido reconhecidamente, nos estudos ambientais vinculados ao planejamento, o principal mecanismo de efetivação das ações no espaço territorial, sejam, por meio de diagnóstico, estudos de impactos, levantamentos físicos e territoriais, seja pela análise socioeconômica, enfim, por mecanismos que possibilitem antever quadros futuros de organização territorial (AMORIM et al., 2008).

Entende-se que o uso e ocupação dos ambientes naturais pelo homem se dão de diferentes maneiras, entre elas por meio do turismo, através de práticas como o ecoturismo. 0 ecoturismo é uma prática que busca conservar o meio ambiente natural através de um relacionamento harmônico entre as ações/atividades humanas e as riquezas naturais do espaço (MAGALHÃES, 2011).

O turismo associado à preservação da natureza surgiu da necessidade de tornar essa atividade econômica, em uma prática também sustentável (MENEZES, 2015). Essa necessidade tornou-se mais evidente ao passo em que inúmeros recursos naturais foram explorados de forma indiscriminada, levando os ambientes naturais a tornarem-se paisagens "minutas", ou seja, pequenas amostras ou reservas do que outrora dominava os diversos espaços geográficos.

O ecoturismo é uma atividade que busca conciliar práticas socioeconômicas junto à conservação dos recursos naturais. Magalhães (2011) afirma que o turista contemporâneo quer conhecer, respeitar e 
participar da conservação dos locais visitados, e que o ecoturismo é importante instrumento de educação, tanto para o turista, como para aquele que vai receber o visitante.

O segmento ecoturístico é recente, datando da década de 1980 os primeiros estudos no Brasil (BRASIL, 2010); já o conceito de Turismo Sustentável é definido como uma postura de preservação social, ambiental, econômica e cultural associada a qualquer atividade turística (MENEZES, 2015). Em relação ao segmento ecoturístico o Ministério do Turismo (BRASIL, 2010), elucida que

Os princípios e os critérios para o desenvolvimento do segmento devem considerar a gestão socioambiental dos recursos naturais, para que os impactos positivos do Ecoturismo sejam maximizados, e os negativos sejam minimizados na esfera ambiental, social e econômica, em especial aos que estão relacionados aos sítios turísticos naturais no Brasil, e àqueles relacionados às Unidades de Conservação que permitem a visitação pública.

Nesse sentindo, o ecoturismo como prática do turismo recreativo, esportivo e/ou educativo, "se utiliza de forma sustentável dos patrimônios natural e cultural, incentiva a sua conservação, promove a formação de consciência ambientalista e garante o bem-estar das populações envolvidas" (MAGALHÃES, 2001). Em consonância com o exposto anterior, Magalhães (2001) afirma que:

O ecoturismo é uma maneira de assegurar a conservação da natureza e aumentar o valor das terras deixadas em estado natural; os lucros financeiros dele provenientes devem reverter para assegurar a conservação ambiental, garantir o seu sucesso como empreendimento econômico e proporcionar reais benefícios às populações residentes.

O uso e ocupação do espaço natural pela sociedade, através de inúmeras práticas, tornaram-se cada vez mais frequente, necessitando-se buscar maneiras e ações para controlar os possíveis problemas ambientais, e despertar a consciência ambiental da sociedade vigente frente à deterioração da qualidade ambiental. Nesse contexto, passa a existir a necessidade de proteger as áreas naturais, as quais apresentam uma grande diversidade biológica, geridas por Leis de acordo com um planejamento e gestão. Surgem assim, as UCs, buscando a preservação e conservação desses ambientes.

\section{Unidades de Conservação e Geoconservação}

Das disposições previstas para as UCs, a gestão ocorre através da implantação de um plano de manejo, o qual é necessário para compreender e elaborar o conjunto de ações responsáveis pela gestão e uso dos recursos naturais, visando cumprir os objetivos estabelecidos na sua criação, os quais foram elaborados levando em consideração características regionais, potencialidades, riquezas naturais e históricas etc., e a partir da prática de uso da natureza e de outras que utilizam os espaços e o meio ambiente para diversas atividades, uso ou ocupação, Freitas (2008) ressalta a importância da criação de áreas protegidas, a exemplo das UCs, como espaços territoriais de harmonia entre homem e natureza. Em se tratando da recuperação e conservação da biodiversidade no contexto das práticas sociais históricas e atuais, Júnior et al. (2009) mostram que:

É impossível considerar a conservação da biodiversidade apenas desafio científico de dimensões ecológica e econômica, com soluções puramente técnicas. As soluções para a degradação da biodiversidade não podem ser reduzidas à substituição de técnicas, porque o status da biodiversidade é uma produção social e sua manutenção ou degradação resulta de processos históricos. 
No que se refere à proteção das áreas naturais, Silva (2001) lembra os conceitos de conservação e preservação, onde: conservação está relacionada ao uso racional dos recursos naturais, evitando a destruição e o desperdício destes; enquanto a preservação é a preocupação com a proteção integral das propriedades naturais de um ou mais ecossistemas. "Tanto a conservação, quanto a preservação dos recursos naturais, objetivam a melhoria das qualidades de vida vegetal, animal e humana" (SILVA, 2007). Uma preocupação mundial, envolvendo todos os países na conservação do bem natural, torna-se a cada dia uma necessidade para diminuir os efeitos negativos das atividades econômicas que ameaçam os recursos naturais ainda existentes.

Ainda de acordo com Silva (2007): "uma rápida devastação das florestas, a perda da biodiversidade, associados aos fundos internacionais disponíveis para gestão e possibilidades dos parques gerarem turismo e renda, fez a transformação das políticas de preservação e conservação"; coibindo até certo ponto, o avanço humano desenfreado, pois se passou a enxergar os problemas socioambientais advindos das atividades humanas predatórias.

Conhecendo-se as inúmeras atividades econômicas predatórias existentes (mineração, desmatamento, pecuária extensiva, etc.), compreende-se o porquê da necessidade da criação das UCs (áreas protegidas em todo o mundo), que se dá em virtude da sua relação aos valores como: riquezas naturais, potencial para recreação e turismo (incluindo-se a caça), proteção de mananciais, de valores históricos com a sustentabilidade local de determinadas comunidades, e em alguns casos, por interesse político (DURIGAN et al., 2006).

O conceito de UC foi tomando forma ao longo dos anos em nível mundial, mas "as áreas protegidas existem no mundo desde o ano de 250 a.C. Nesta época, na Índia, já eram protegidos certos animais, peixes e áreas florestadas" (SILVA, 2007). Diante da preocupação em relação ao meio ambiente e aos recursos naturais, Hassler (2005) lembra que:

A partir da criação do Parque Nacional de Yellowstone, nos Estados Unidos, no ano de 1872, tem início uma nova fase nos procedimentos de conservação ambiental. No histórico da proteção às áreas naturais, a criação do referido parque se reveste de importância fundamental a partir do momento em que as atividades de conservação passam a ser assumidas oficialmente pelo Estado, gerenciando os espaços conservacionistas a partir de interesses e do poder público.

Deste modo, o surgimento deste parque aparece como uma forma de se colocar ordem no "caos" provocado pelas ações humanas e de fortalecer o seu contato harmônico com a natureza, o qual havia se perdido. No entanto, Medeiros et al. (2011) mostram que as UCs não são espaços "intocáveis", de qualquer atividade humana como imaginam algumas pessoas sobre os espaços protegidos.

Diante da importância das UCs na preservação/conservação de áreas naturais, Hassler (2005) afirma, após estudos no Brasil, que tais espaços "passam a ter uma importância cada vez maior, principalmente na década de 1990, período de maior globalização dos problemas ambientais". O que acaba contribuindo para que se tenha uma maior preocupação e atenção com as mesmas.

A criação das UCs foi constituída pela Lei no 9.985/2000, que criou o Sistema Nacional de Unidades de Conservação da Natureza (SNUC), que define, uniformiza e consolida critérios para o estabelecimento e a 
gestão de áreas protegidas, compostas pelo conjunto: Federal, Estadual e Municipal, distribuídas em categorias de manejo. Os usos e manejos dos recursos naturais permitidos dentro de cada UC variam conforme sua categoria, a qual é definida a partir da vocação fisiográfica e da diversidade de fauna e flora que a área possui (BRANDÃO et al., 2012).

As UCs acabam cumprindo e contribuindo de forma efetiva, com uma série de funções diante de desafios e problemas contemporâneos, um dos exemplos mais relevante é a mudança climática. As UCs ajudam a reduzir o aumento da concentração de gases na atmosfera terrestre, mitigando a emissão de gases de efeitos estufa decorrente da degradação de ecossistemas naturais, além de fornecer benefícios, destacando-se: a água que compõe os reservatórios de usinas hidrelétricas pela sua qualidade e quantidade, assegurada por UC, provendo energia a cidades e indústrias (MEDEIROS et al., 2011).

No Brasil, a criação das UCs teve inicialmente a proposta de dois parques em 1876, mas apenas em 1937 teve sua primeira Unidade implantada: o Parque Nacional de Itatiaia, localizado no município de ItatiaiaRJ, "criado com a finalidade de promover a pesquisa científica e a atividade turística" (MAGALHÃES, 2001). Ainda no tocante a criação das UCs, tem-se, segundo Brandão et al. (2012)

As Unidades de Conservação são criadas por ato do Poder Público, cuja orientação, contida no art. 225 da Constituição Federal, informa que o meio ambiente ecologicamente equilibrado é um bem de uso comum do povo e essencial à sadia qualidade de vida, e que, para efetividade desse direito, o poder público fica incumbido de definir, em todas as unidades da federação, espaços territoriais e seus componentes a serem especialmente protegidos, sendo a alteração e a supressão permitidas somente através de Lei, vedada qualquer utilização que comprometa a integridade dos atributos que justifiquem sua proteção.

As UCs se dão não apenas para áreas do território, mas também do mar brasileiro, onde seus limites são demarcados, sujeitos a um uso ou ocupação especial, com valor cênico e paisagístico dos recursos ambientais, onde se encontram ecossistemas únicos que devem ser protegidos (MAGALHÃES, 2001). A necessidade em criar o SNUC surge diante dos problemas encontrados inicialmente nas criações das UCs, que foi sendo feita de forma desorganizada e até então não obedecia às normas capazes de garantir a sua eficácia, necessitando dessa maneira, desenvolver um sistema que pudesse corrigir a confusão gerada por inúmeras Leis, e promover um ordenamento diante da situação (MAGALHÃES, 2001). "A concepção de uso público das unidades de conservação evoluiu de forma conjugada às mudanças na própria concepção de como planejar e gerir a conservação da natureza no Brasil" (BRASIL, 2001). Representou, portanto, um papel importante dentro da política nacional de áreas protegidas no país.

A Lei 9.985/2000 estabelece dois grupos de UCs: as de Proteção Integral e as de Uso Sustentável (MEDEIROS et al., 2011). Considerando os tipos de manejo e os dois grupos estabelecidos pela Lei 9.985/2000, encontra-se dentro das UCs de Proteção Integral: Estação Ecológica (EE), Reserva Biológica (REBIO), Parque Nacional (PARNA), Parque Estadual (PAREST), Monumento Natural (MN), e o Refúgio da Vida Silvestre (RVS). Essa primeira categoria no tipo de uso tem como objetivo básico a preservação da natureza, sendo apenas admitido o uso indireto de seus recursos naturais, isto é, usos que não envolvam o consumo, coleta, dano ou destruiç̧ão de tais recursos (MAGALHÃES, 2001; MEDEIROS et al., 2011). 
No segundo grupo, de Uso Sustentável, encontram-se: a Área de Proteção Ambiental (APA), Área de Relevante Interesse Ecológico (ARIE), Floresta Nacional (FLONA), Floresta Estadual (FLOEST), Reserva Extrativista (RE), Reserva de Fauna (RF), Reserva de Desenvolvimento Sustentável (RDS) e a Reserva Particular de Patrimônio Natural (RPPN). Ao contrário das UCs de Proteção Integral, as UCs de Uso Sustentável têm como objetivo compatibilizar a conservação da natureza com o uso sustentável de parcela de seus recursos naturais, entendido esse tipo de uso sustentável como "exploração do ambiente de maneira a garantir a perenidade dos recursos renováveis e dos processos ecológicos, de forma socialmente justa e economicamente viável" (MAGALHÃES, 2001; MEDEIROS et al., 2011).

Por apresentar muitos Parques no território brasileiro, as UCs propiciam a maior variedade de experiências e maior interação entre o visitante e a natureza, sendo áreas abertas à ação humana, embora sejam Unidades de Proteção Integral. O uso dos Parques é conhecido devido à importância que eles têm para a recreação, turismo ecológico e educação ambiental (BRASIL, 2011).

A criação do SNUC é vista como um dos modelos mais sofisticados do mundo, indo além da manutenção da biodiversidade dentro de sua concepção, possibilitando diversos usos do solo e dos recursos naturais, contribuindo para a realização de diversas atividades, sem prejuízo da conservação ambiental. Com maior representatividade dentro de suas categorias estão: os Parques e as Áreas de Proteção Ambiental, abrangendo e protegendo no Brasil 53\% da área das UCs (BRASIL, 2011).

O SNUC regulamentou o art. 225, do Capítulo VI, objetivando com que todos os cidadãos tenham direito ao meio ambiente equilibrado, com igualdade no uso dos espaços, além de contribuir para a boa qualidade de vida de todos. Ele fez com que "o Poder Público, junto com a coletividade, devam preservar e defender o meio ambiente para as presentes e futuras gerações" (SILVA, 2001). Para o Ministério do Meio Ambiente (BRASIL, 2011), seu objetivo é despertar o interesse da sociedade pelo patrimônio natural e cultural protegido pelo Poder Público, aproximando as UCs das pessoas, devendo ser entendidas como uma maneira especial de ordenamento territorial e não como entrave para o desenvolvimento econômico e social.

Com o intuito de preservar, conservar e proteger a natureza e os recursos naturais que fazem parte nos espaços territoriais, o SNUC "têm a função de assegurar a representatividade de amostras significativas e ecologicamente viáveis das diferentes populações, habitat e ecossistemas do território nacional e das águas, preservando o patrimônio biológico existente" (BRANDÃO et al., 2012). Além disso, o SNUC deve definir, uniformizar e consolidar os critérios de estabelecimento da gestão das UCS (SILVA, 2007).

Diante disso, vem-se fortalecendo o conceito de Geoconservação, uma das mais novas vertentes da conservação da natureza e da paisagem. Para Brilha (2005) a Geoconservação reconhece que através do processo de conservação da natureza, o componente abiótico é tão importante quanto o componente biótico; ela está relacionada com diferentes eixos estruturantes, como o ordenamento do território, política educativa, e turismo de natureza.

Resumidamente, a Geoconservação é um ramo da atividade científica que tem como objetivo principal a caracterização, conservação e gestão do patrimônio geológico e dos processos naturais 
associados; avaliando, selecionando e priorizando as iniciativas alusivas à Geoconservação (BRILHA, 2005). Assim, a Geoconservação constitui-se na busca de ações e formas práticas de conservação das riquezas naturais, ofertando a harmonia entre as atividades socioeconômicas e a conservação dos recursos naturais existentes localmente, relacionando-se uso desses espaços.

\section{Zona de Amortecimento de UC}

Dois conceitos fundamentais estão previsto no Código Floresta Brasileiro Lei № (12.651/12) e no Sistema Nacional de Unidades de Conservação (SNUC) Lei no (9985): o primeiro é o de Zona de Amortecimento (ZA), e o segundo é o de Corredores Ecológicos (CE), que representam um esforço de segurança e conservação da biodiversidade além dos limites das UCs (MACHADO, 2014). Estes têm sido amplamente discutidos em congressos científicos, na Câmera dos Deputados e no Senado Federal, repercutindo nas discussões que envolvem UCs.

As ZA são delimitações periféricas que ultrapassam os limites políticos das UCs, não fazem parte da unidade, mas promovem a estabilidade ecológica segura à sua biodiversidade. Já os CE procuram mitigar os efeitos da fragmentação e insularização dos ambientes naturais, a qual prejudica ou mesmo inviabilizam a manutenção da biodiversidade em função da redução e isolamento dos ecossistemas, através da conectividade de áreas preservadas (CAMPOS et al., 1997; MACHADO, 2014).

Nessa discussão, Machado (2014) diz que na ZA todas as atividades antrópicas que possam afetar a biota num raio estimado de até dez quilômetros $(10 \mathrm{~km})$, posterior ao limite político da UC, deverão estar licenciadas e monitoradas pelo órgão ambiental administrador da UC. O tamanho da ZA se acomoda as UCs levando-se em consideração parâmetros geográficos, biológicos e sociais, podendo estes estar contidos no Zoneamento Ecológico-Econômico da área, caso haja.

Assim, diante da carência de informações seguras e confiáveis acerca da realidade que envolve o contexto socioambiental do Parque Estadual Mata do Pau Ferro, buscou-se contribuir com conhecimentos técnico-científicos sobre o uso e ocupação e como as atividades humanas locais tem contribuído, de forma positiva ou negativa, para a conservação ou deterioração da qualidade ambiental local. Assim, a pesquisa se justifica por relacionar as potencialidades locais e abordar a necessidade de conciliar os interesses socioeconômicos às premissas de conservação e preservação dos recursos naturais. Nesse sentido, o objetivo da pesquisa foi: analisar o uso e ocupação do Parque Estadual Mata do Pau Ferro, Areia/PB, com vistas a identificar os possíveis problemas, benefícios e potencialidades no tocante a conservação dos recursos naturais, como subsídio a geoconservação.

\section{METODOLOGIA}

\section{Área de pesquisa}

Os estudos foram realizados no Parque Estadual Mata do Pau Ferro, o qual está localizado no município de Areia-PB, conforme ilustrado na Figura 1. O Município está localizado na mesorregião do 
Agreste e microrregião do Brejo paraibano, ocupando uma área de $269,4 \mathrm{~km}^{2}$, e detém uma população de 23.829 habitantes (IBGE, 2015).

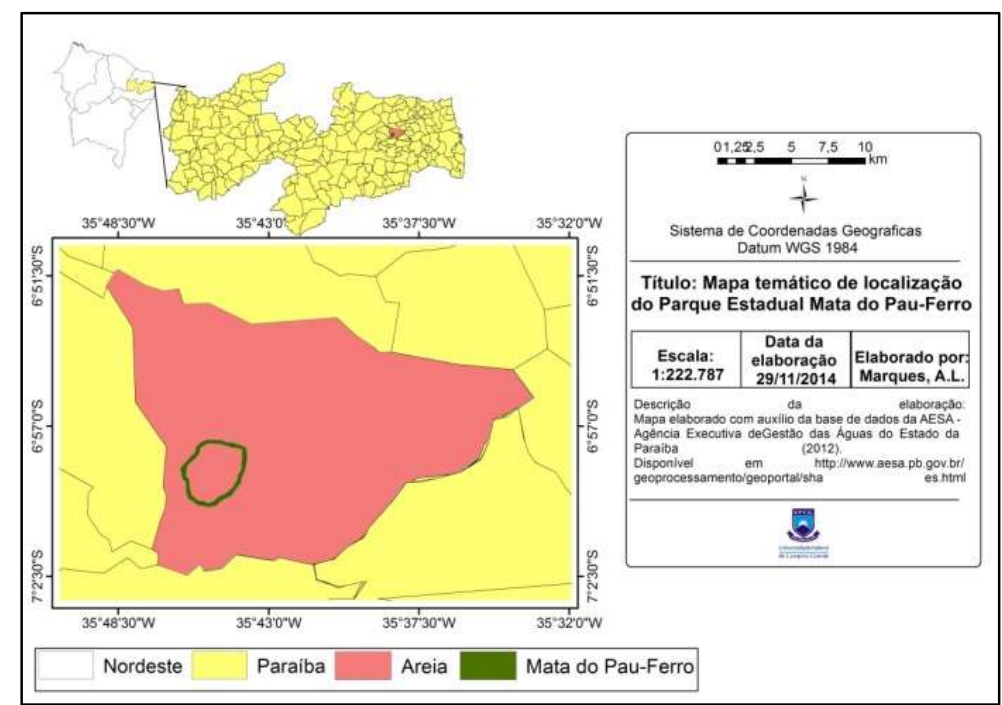

Figura 1: Mapa de localização do Parque Estadual Mata do Pau Ferro.

O município de Areia/PB possui clima do tipo As', ou seja, tropical chuvoso, quente e úmido, de acordo com a classificação de Köppen. As chuvas são de outono e inverno, com precipitação anual oscilando entre 800 e 1600 mm, concentradas nos meses de junho a agosto, com temperaturas máximas e mínimas de 26 ㄷ e 18ํㅡ, respectivamente. A precipitação pluviométrica dos domínios geomorfológicos situa-se em torno de $1.400 \mathrm{~mm}$ anuais e o conjunto dos elementos naturais resultantes desse quadro, forma os chamados Brejos de Altitude (MARQUES et al., 2014; SILVA, 2007).

O relevo apresenta configurações de vales, várzeas, morrotes e morros dissecados em posição de barlavento. A geologia está sob predomínio da unidade morfológica do Planalto da Borborema, formado basicamente pelo domínio da grande Província do Cristalino, em cuja composição predominam rochas do Complexo Gnaisse-Migmatítico, como pegmatitos, granitos, quartzitos etc, além de coberturas sedimentares oriundas da Formação Serra dos Martins (MARQUES et al., 2014).

Assim, o município apresenta diferenciadas condições de umidade e pedogênese (solos férteis) fazendo com que apresente características diferentes quanto à vegetação, apresentando o domínio biogeográfico da Mata Atlântica e ecossistemas associados, e umidade considerada satisfatória para a agricultura.

Sendo um dos poucos remanescentes florestais dos Brejos de Altitude do interior do Nordeste, a "Mata do Pau Ferro" é a maior UC de proteção integral, preservando as nascentes de rios afluentes da bacia do rio Mamanguape e a barragem Vaca Brava que abastece populações de vários municípios do Estado. A condição do brejo propicia o surgimento de Floresta Ombrófila Aberta, sitiada pela vegetação de caatinga que ganha espaço em meio ao remanescente de Mata Atlântica, a qual detém uma elevada biodiversidade. No caso em análise, o surgimento de Floresta Ombrófila ocorre a barlavento do Planalto da Borborema, cujos flancos verticalizados forçam a subida do ar, carregado de umidade, a cotas de aproximadamente $600 \mathrm{~m}$, ocasionando as chuvas orográficas (ANDRADE et al., 2006). 
No tocante ao Parque Estadual Mata do Pau Ferro, esse possui, aproximadamente, 599 hectares; sendo uma UC da Mata Atlântica, a qual foi constituída em 19 de outubro de 1992 pelo Decreto nํㅜ 14.832, criada como Reserva Ecológica, passando a ser Parque Estadual em 2005. Tendo como objetivos: preservar a biodiversidade e os ecossistemas naturais; proteger a beleza cênica; proteger espécies raras, endêmicas, e vulneráveis ou em perigo de extinção (ANDRADE et al., 2006; SILVA, 2007).

\section{Procedimentos metodológicos}

A base metodológica adotada neste trabalho fundamentou-se em diferentes bibliografias referentes às Unidades de Conservação, às práticas de Conservação e Preservação, além da busca de fundamentos teóricos sobre o Turismo, Ecoturismo e uso e ocupação nas UCs.

Para os estudos, foi realizada uma pesquisa in loco, onde foi possível, através do método de observação e da aplicação de questionário, identificar e analisar alguns aspectos:
a) as condições das instalações no Parque;
b) o fluxo de visitantes/turistas;
c) o uso e ocupação do espaço local;
d) possíveis problemas ambientais, como produção de resíduos, desmatamento, degradação da fauna e flora etc.;
e) os benefícios socioambientais do Parque; e
f) os anseios populares (visitantes, moradores) para com o uso e conservação dos recursos naturais existentes localmente.

Cabe ressaltar que os questionários foram semiestruturados, com perguntas direcionadas à população local e pesquisador. Referindo-se à pesquisa de campo, realizou-se o registro de fotografias, nas quais se priorizou a identificação dos problemas socioambientais, e o conhecimento da fisiografia natural da área, isso a partir do método Geossistêmico. Contribuindo na análise e identificação dos aspectos físicos, o que contribuiu para caracteriza reconhecer os elementos naturais (fisiográficos), como relevo, solo, clima, hidrografia e vegetação.

Através de sensoriamento e geoprocessamento, utilizando as plataformas Erdas 2010 e ArcGIS 10, procedeu-se o mapeamento do uso da terra na simulação de zona de amortecimento. Foi processada a imagem no Landsat8, em 16/08/2014, adquirida na plataforma do USGS - Serviço Geológico Americano. Esta passou pela: Calibração radiométrica e de reflectância, e aplicando-se o método Máxima Verossimilhança (MAXVER). Posteriormente, criaram-se assinaturas espectrais para obtenção de classes de uso e ocupação territoriais, no intuito de identificar e espacializar as respostas: Lavouras diversificadas, Pastagens, Vegetação Florestal e Água, e, por conseguinte, foi estabelecida a simulação de $1 \mathrm{~km}$ de extrapolação marginal utilizando o método de Buffer do ArcGIS 10, para delimitar a ZA e embasa a análise através da imagem. Após esse processo, foram analisadas imagens do Google Earth, em 12/09/2015.

Os softwares Erdas Imagine 10, ArcGIS 10 e Google Earth Pro, estão licenciados para o Laboratório Multiusuários de Tecnologias da Informação Aplicadas às Ciências Humanas (LabINFO), setor de Cartografia 
digital, Geoprocessamento e Sensoriamento Remoto (CADIGEOS), do Centro de Humanidades da Universidade Federal de Campina Grande (UFCG).

Por fim, com o auxílio da revisão bibliográfica referente à temática deste trabalho, foram identificados os problemas socioambientais correlacionados ao uso e ocupação do espaço, assim como também as riquezas fisiográficas que denotam potencialidades para a prática de atividades econômicas que harmonizem interesses econômicos e conservação/preservação dos recursos naturais locais.

\section{RESULTADOS E DISCUSSÕES}

Mediante as informações obtidas e constatadas em campo através de observações diretas e de entrevistas com moradores, pesquisador e responsável pelo Parque Estadual Mata do Pau Ferro, constatouse a presença de atividades humana no mesmo, como habitações, desmatamento, degradação do ambiente, área de cultivo e pastagem, além de a identificação de algumas características fisiográficas referente às riquezas naturais: solo, vegetação, clima e hidrografia.

Dentro da Unidade, a agricultura e a pecuária são atividades facilmente encontradas em diversos pontos, como observado na figura 2. Entre as diferentes culturas no interior da Mata do Pau Ferro, foram encontradas plantações de banana, caju e cana de açúcar, e de subsistência, como feijão, mandioca e milho; notou-se também de algumas hortaliças; tudo isso pode ser verificado na figura $2 \mathrm{~A}$. Essas áreas ainda contam com cercas para delimitar, pode-se dizer territorizar o espaço até então ocupado e utilizado, sem levar em consideração quaisquer tipos de regras ou leis que impeça as ações por parte da população.

Logo, percebe-se que para a realização dessas práticas, várias áreas foram desmatadas possibilitando o cultivo de culturas de subsistência e pastagem de animais, por parte dos moradores do parque ou do entorno, que possuem animais de diferentes portes e utilizam-se do espaço como área de pastagem, de acordo com o explicitado na figura 2B. Essas comunidades mantêm essas atividades (a agricultura e pecuária) como principais fontes de renda, ou então complemento da renda familiar.
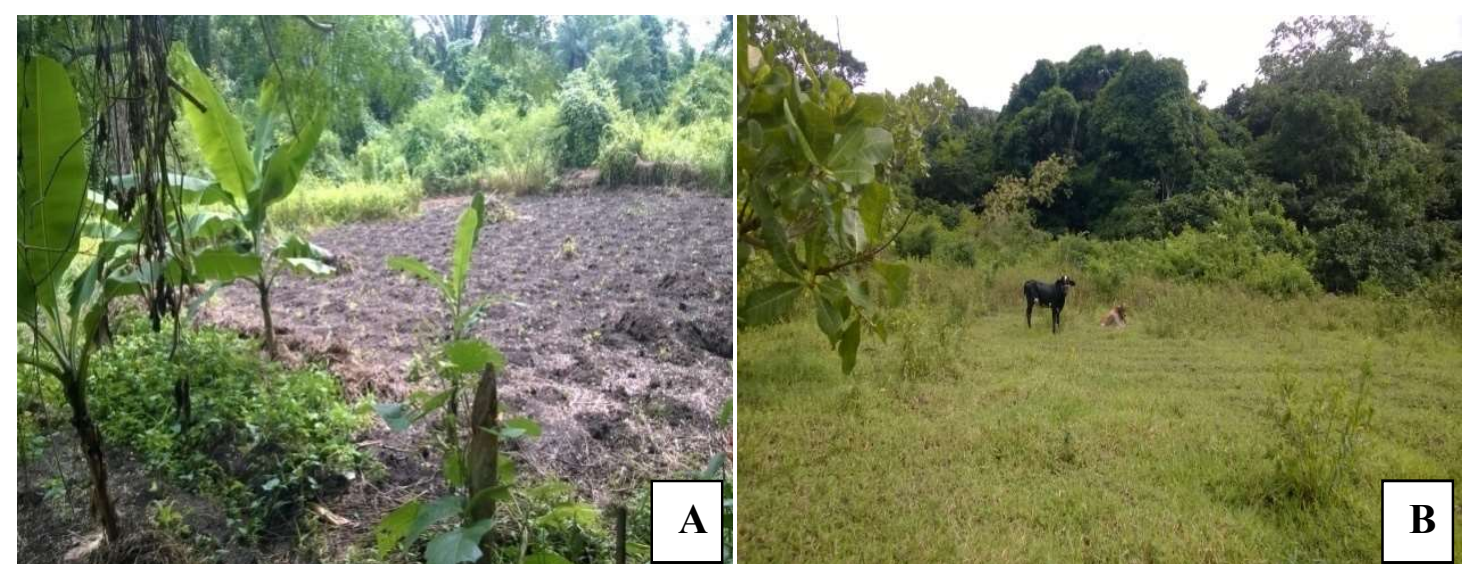

Figura 2: Agricultura e pecuária no interior do Parque. Fonte: Barbosa (2016).

Essas atividades inerentes às ações humanas se tornam um dos principais problemas e pontos negativos ao se tratar de uma área de proteção integral, que deveria apenas admitir o uso indireto de seus recursos naturais, com a sua preservação e conservação. No entanto, constataram-se problemas referentes 
à deficiência na gestão e fiscalização dessas atividades. Vale relembrar que estas atividades ilegais, são de conhecimento dos representantes legais, mas estes não tomam iniciativas para tratar a situação. Segundo um dos entrevistados, professor-pesquisador da Universidade Federal da Paraíba, Campus de Areia, os responsáveis não tomam qualquer medida cognitiva. 0 mesmo fez diversas denúncias formais e de nada adiantou, e afirmou que os responsáveis são completamente omissos diante de tais situações.

A evidência das habitações no interior do Parque é outro ponto negativo dentre os diversos problemas até então identificados. Logo, questiona-se a respeito das regras impostas quanto às habitações no interior de UCs, principalmente quando se refere à de proteção integral. Mesmo após a construção de habitações populares na entrada do Parque, nas proximidades da rodovia, pelo Governo Estadual, alguns moradores se recusaram a sair do interior da Mata, permanecendo nessa área. Em consequência dessas atividades e do desmatamento provocado, acabam por se encontrar clareiras, áreas abertas em consideráveis números.

\section{Zona de Amortecimento - ZA}

In loco, referindo-se ao Parque, não elucidaram se há vigilância e projetos de educação ambiental para as comunidades inseridas no entorno da UC, assim como monitoramentos dos recursos naturais, podendo se encontrar áreas sob manejo agrícola rudimentar no seu interior, como visto anteriormente. De acordo com o uso e ocupação da UC Parque Estadual Mata do Pau Ferro e sua Zona de Amortecimento (ZA), verificou-se que o grau de intervenção antrópica tanto dentro do Parque, como na ZA se dão por alastramento de lavouras e pastagens, além disso, não há CE, conforme a figura 3.

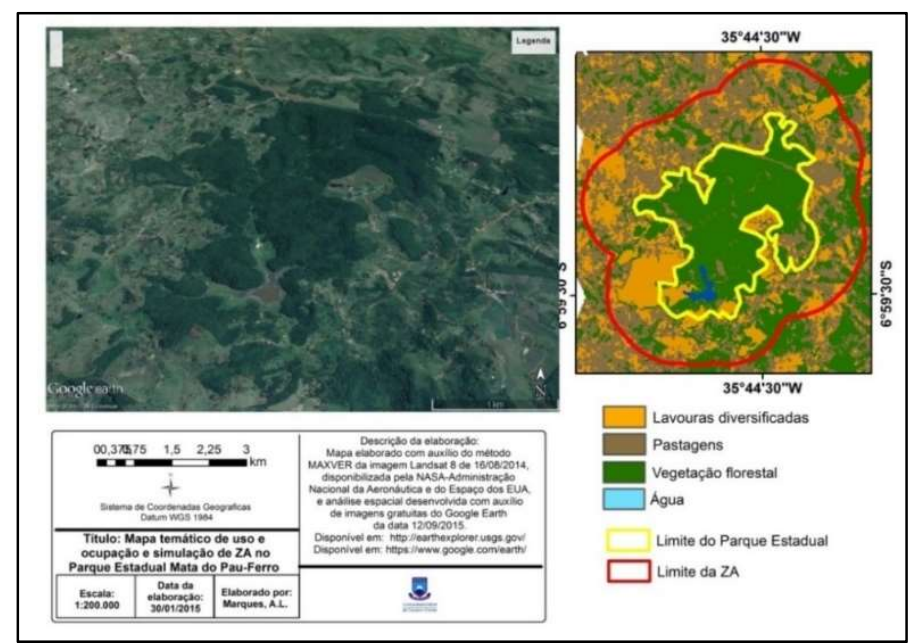

Figura 3: Uso e ocupação da terra e simulação de ZA para o Parque Estadual Mata do Pau-Ferro, Areia/PB.

Identificou-se, na superfície terrestre, diferentes tipos de respostas espectrais, ou seja, como cada objeto respondeu ao sensor de satélite, como: lavouras diversificadas, pastagens, vegetação florestal e água, como proposto na tabela 1, possibilitando a análise do uso e ocupação nos hectares que compreende a ZA e a UC, e quais os principais elementos cultivados nessas áreas. Dessa forma, compreende-se a simulação feita de (1) km para a ZA em relação à UC, e cada resposta espectral obtida no estudo, identificando os principais elementos e intervenções humanas. 
Tabela 1: Classificação da terra na Zona de Amortecimento do Parque Estadual Mata do Pau Ferro, Areia-PB.

\begin{tabular}{|c|c|c|c|c|}
\hline \multirow{2}{*}{$\begin{array}{l}\text { Resposta } \\
\text { espectral }\end{array}$} & $\begin{array}{l}\text { Ha no } \\
\text { Parque } \\
\end{array}$ & $\begin{array}{c}\text { Ha na } \\
\text { ZA }\end{array}$ & \multirow[t]{2}{*}{ Elementos principais } & \multirow[t]{2}{*}{ Usos e ocupação } \\
\hline & 599 & 900 & & \\
\hline $\begin{array}{l}\text { Lavouras } \\
\text { diversificadas }\end{array}$ & 10 & 374 & $\begin{array}{l}\text { Bananeiras, cana de açúcar (engenhos), frutíferas } \\
\text { exóticas, hortaliças e leguminosas. }\end{array}$ & $\begin{array}{l}\text { Usos monocultores e } \\
\text { propriedades familiares. }\end{array}$ \\
\hline Pastagens & 5 & 404 & Gramíneas e áreas vegetadas esparsas. & Pecuária e área de pousio. \\
\hline $\begin{array}{l}\text { Vegetação } \\
\text { florestal }\end{array}$ & 576 & 122 & $\begin{array}{l}\text { Floresta ombrófila aberta e floresta estacional em } \\
\text { sucessão. }\end{array}$ & $\begin{array}{l}\text { Parque Estadual e reservas } \\
\text { particulares. }\end{array}$ \\
\hline Água & 8 & $\mathrm{x}$ & $\mathrm{x}$ & $\mathrm{X}$ \\
\hline
\end{tabular}

Essas atividades, no entanto, geram uma discussão referente à utilização e conflitos nessa área, visto que, a criação da UC se deu como uma Reserva Extrativista, e dessa forma, potencializava atividades extrativistas, podendo ser executadas em florestas, como a Mata do Pau Ferro, ou seja, pessoas cultivavam já que até então não existiam leis que proibisse as práticas dessas atividades. Porém, viu-se que a Mata do Pau Ferro não se encaixaria como RE, sendo tombado como Parque Estadual, logo de proteção integral e efetiva da área, e não mais uma difusão de atividades extrativistas; limitando assim, o que é executado dentro da área, apesar de que em tese não vem sendo respeitado por parte da população, e atividades dentro do Parque são executadas mesmo sendo proibidas.

\section{Potencial Ecoturístico}

Construído para atender os moradores após a retirada de diversas famílias que moravam no interior da área da Mata, o Centro de Ecoturismo Jonas Camelo de Sousa, ilustrado na figura 4, é uma vila com várias casas e uma usina de beneficiamento de frutas e castanhas, beneficiando a comunidade local. Dentre essas instalações, uma delas (um pequeno salão) serve para atender os turistas/visitantes do parque.

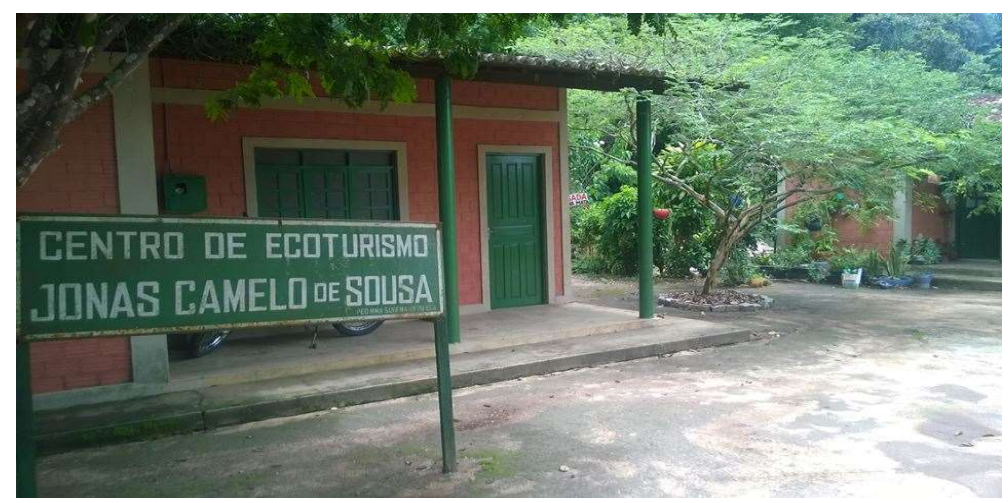

Figura 4: Centro de apoio ao ecoturismo. Fonte: Barbosa (2016).

Segundo uma das entrevistadas que possui certo conhecimento sobre a área, moradora, guiaturística na região e responsável por administrar o restaurante "Vó Maria", que serve para atender os visitantes do parque, é frequente a presença de turistas no Parque, principalmente nos meses de abril a novembro, em média de 600 visitantes nesse período.

As atividades de ecoturismo, como lembra Magalhães (2011), é uma prática que envolve o turista e sua participação na preservação dos ambientes. Indo contrário a essa afirmação, as atividades e os problemas 
encontrados mostram que na prática a sociedade não leva em consideração o real conceito de ecoturismo e da geoconservação, onde deveria moradores e visitantes, respeitar e participar da conservação do ambiente.

As riquezas naturais como o rio existente e a própria mata em si, propicia diversas atividades para os visitantes, destacando-se as: trilhas que dão acesso a diferentes pontos no parque e facilita o conhecimento da área; piquenique; passeio de bicicleta ou a cavalo; e os esportes radicais (arborismo, tirolesa) para os mais aventureiros. Todas essas atividades são exemplos da utilização por parte dos visitantes, que buscam nesse espaço relacionar-se com a natureza.

Além daqueles que buscam conhecer e visitar para realizar atividades e práticas ecoturísticas, outro potencial do Parque diz respeito a sua importância para estudos e pesquisas. Nesse sentido, satisfatoriamente em números, boa parte dos visitantes é de grupos de estudantes da educação básica, discentes e docentes universitários do Estado da Paraíba e de outros estados, além da existência do Campus da UFPB e sua influência para estudos nesse espaço.

\section{CONCLUSÕES}

O Parque Estadual Mata do Pau Ferro, apresenta-se como um verdadeiro coração verde, imprescindível para manter a biodiversidade, e proteger o remanescente de Mata Atlântica e os recursos naturais e hídricos. Pôde-se perceber o grau da intervenção humana através do uso e ocupação ilegal como alternativa para sobrevivência de alguns, o que contribui para a degradação ambiental área. Com isso há urgência na recuperação da área, com benfeitorias que objetivam melhorar a qualidade de vida da comunidade local e a preservação dos recursos naturais.

Em toda ZA há fragmentação com resquícios de florestas pressionados e em vários estágios sucessionais. Comumente, essas áreas são desmatadas para utilização agrícola (pousio e rotação de culturas), originando assim, um conflito socioambiental. Os monitoramentos e licenciamentos, nessas circunstâncias, permitiriam recompor as Áreas de Preservação Permanentes e reflorestar com espécies nativas as áreas mais sensíveis, propiciando também o retorno de espécies polinizadoras e dispersoras, que ajudariam no equilibro sistêmico ambiental de toda ZA.

Nesse sentido, é necessário o despertar da população para a participação intensa na proteção desse espaço. As ações da comunidade e dos visitantes podem transformar e valorizar o ecoturismo positivamente, bem como a preservação dos recursos hídricos, uma vez que o Parque abriga um reservatório de inestimável importância para atender as diversas famílias.

O estudo realizado evidencia que é necessário melhorar muito em termos de gestão, consolidando o que se propõe a UC de proteção integral, com mecanismos que possam reverter o quadro atual. E diante da falta de gestão no Parque, fica evidente que os objetivos da institucionalização da UC Mata do Pau Ferro não vêm sendo alcançados em virtude, principalmente, da falta de comprometimento com a gestão da área, e do principal órgão responsável, SUDEMA, o qual deveria contribuir no monitoramento ambiental. 


\section{REFERÊNCIAS}

AMORIM, R. R.; OLIVEIRA, R. C.. As Unidades de Paisagem como uma categoria de análise geográfica: o exemplo do município de São Vicente/SP. Revista Sociedade e Natureza, Uberlândia, 2008.

ANDRADE, L. A.; OLIVEIRA, F. X.; NASCIMENTO, I. S.; FABRICANTEE, J. R.; SAMPAIO, E. V. S. B.; BARBOSA, M. R. V.. Análise florística e estrutural de matas ciliares ocorrentes em brejo de altitude no município de Areia, Paraíba. Revista Brasileira de Ciências Agrárias, Recife, v.1, 2006.

BERTRAND, G.. Paisagem e geografia global: esboço metodológico. Cadernos de Ciências da Terra, São Paulo, n.13, 1971.

BRANDÃO, E. J.; VIEIRA, E. M.. Instrumentos de gestão ambiental nas unidades de conservação. Revista do Curso de Direito da Associação Brasileira de Ensino Universitário. v.2, n.1, 2012.

BRASIL. Ministério do Meio Ambiente. O Sistema Nacional de Unidades de Conservação da Natureza. Brasília: 2011.

BRASIL. Ministério do Turismo. Ecoturismo: Orientações básicas. 2. ed. Brasília: 2010.

BRILHA, J.. Património Geológico e Geoconservação: a conservação da natureza na sua vertente geológica. Braga: Palimage, 2005.

CAMPOS, J. B.; AGOSTINHO, A. A.. Corredor de fluxo de biodiversidade do rio Paraná: uma proposta de integração e proteção ambiental de ecossistemas ameaçados. In: CONGRESSO BRASILEIRO DE UNIDADES DE CONSERVAÇÃO. Anais. Curitiba: 1997.

CHRISTOFOLETTI, A.. Modelagem de sistemas ambientais. São Paulo: Edgard Blücher, 1998.

DURIGAN, G.; SIQUEIRA, M.F.; FRANCO, G. A. D. C.; RATTER, J. A.. Seleção de fragmentos prioritários para a criação de unidades de conservação do Cerrado no estado de São Paulo. Revista do Instituto Florestal, São Paulo, v.18, 2006.

FREITAS, C. D.. A Educação Ambiental nas Unidades de Conservação. Nova Lima: Sinapse Ambiental, 2008.

HASSLER, M. L.. A importância das Unidades de Conservação no Brasil. Revista Sociedade e Natureza, Uberlândia, v.17, n.10, 2005.

JÚNIOR, E. C.. Gestão da biodiversidade e áreas protegidas. In: GUERRA, A. J. T.; COELHO, M. C. N.. Unidades de Conservação: abordagens e características geográficas. Rio de Janeiro: Bertrand Brasil, 2009.

MACHADO, C. C. C.. Alterações da superfície no Parque Nacional do Catimbau (PE - BRAZIL): indicadores biofísicos e influência humana. Tese (Doutorado) - Universidade Federal de Pernambuco, Recife, 2014.

MAGALHÃES, G. W.. Pólos de ecoturismo: planejamento e gestão. São Paulo: Terragraph, 2001.

MARQUES, A. L.; SILVA, J. B.; SILVA, D. G.. Compartimentação Geomorfológica e Geoambiental da Bacia do Rio Mamanguape. Campina Grande: UEPB, 2014.

MEDEIROS, R.. Contribuição das unidades de conservação brasileiras para a economia nacional: Sumário Executivo. Brasília: UNEP, 2011.

MENEZES, B. F. R.. Ecoturismo em Unidades de Conservação. In: ENCONTRO FLUMINENSE DE USO PÚBLICO EM UNIDADES DE CONSERVAÇÃO, 2. Anais. Niterói: 2015.

NASCIMENTO, F. R.; SAMPAIO, J. L. F.. Geografia física, geossistemas e estudos integrados da paisagem.

Revista Casa da Geografia de Sobral, Sobral, v.7, n.1, 2005.

SILVA, M. C.. Degradação ambiental na reserva ecológica estadual Mata do Pau Ferro-Areia/PB. Dissertação (Mestrado em Geografia) - Universidade Federal da Paraíba, João Pessoa, 2007.

SILVA, M. C.; LIMA, E. R. V.; QUEIROZ, J. E. R.. A Reserva Ecológica Estadual da Mata do Pau Ferro e sua importância como unidade de planejamento e gerenciamento dos Recursos Hídricos para o Reservatório de Vaca Brava Areia-PB. Caminhos de Geografia, Uberlândia, v.16, n.6, 2005.

SILVA, M. C.; QUEIROZ, J. E. R.. Uso de Geoprocessamento no Estudo de Ações Antrópicas: Estudo de Caso - Reserva Ecológica Estadual da Mata do Pau Ferro Areia/PB: Campina Grande: UEPB, 2001.

SUERTEGARAY, D. M. A.. Geografia física, Geografia ambiental, ou Geografia e ambiente?. In: MENDONÇA, F.; KOZEL, S.. Elementos de epistemologia da Geografia contemporânea. Curitiba: UFPR, 2002.

TROPPMAIR, H.; GALINA, M. H.. Geossistemas. Mercator, Fortaleza, v.5, n.10, 2006. 